\title{
GDP Is Well-Being! Results in the USA and China
}

\author{
Gordon Bechtel \\ Warrington College of Business, University of Florida, Gainesville, FL, USA \\ Email: bechtel@ufl.edu
}

How to cite this paper: Bechtel, G. (2019) GDP Is Well-Being! Results in the USA and China. Open Journal of Social Sciences, 7 , 189-204.

https://doi.org/10.4236/jss.2019.712014

Received: October 30, 2019

Accepted: December 6, 2019

Published: December 9, 2019

Copyright $\odot 2019$ by author(s) and Scientific Research Publishing Inc. This work is licensed under the Creative Commons Attribution International License (CC BY 4.0).

http://creativecommons.org/licenses/by/4.0/

\section{c) (i) Open Access}

\begin{abstract}
This article quality assures GDP and then links it to well-being in the world's two largest economies. Despite the global plethora of national indexes, there has been little quality assurance of the unidimensionality of their component indicators. Unidimensional index theory constructs a weighted composite from a 2-level principal components analysis of its several indicators. This weighted composite evaluates its unweighted counterpart, and informs governments about the allocation of resources over its composite indicators. Two axioms predict that weighted and unweighted indexes are perfectly correlated over successive yearly populations in the USA and China. Under these axioms, fractional polynomial regressions of any criterion on these weighted and unweighted indexes perfectly predict this criterion. We confirm the unidimensionality of American and Chinese GDP indexes and their near-perfect prediction of the United Nation's Human Development Index (HDI). This application discovers that HDI computation can be carried out from a nation's GDP alone, i.e., without survey sampling, questionnaire interrogation, probabilistic inference, significance testing, or even HDI data.
\end{abstract}

\section{Keywords}

Country Specificity of Fractional Polynomial Regressions, Internal Consistency of Keynesian Indicators, 2-Level Principal Components Analysis, Unidimensional Index Theory, Prediction of HDI from Weighted and Unweighted GDP

\section{Introduction: The Keynesian Construct}

John Maynard Keynes deplored the vindictive Versailles Treaty ending World War I, saved the United States in the depth of the Great Depression, and went on to construct our gross domestic product (GDP). This paper views his three clas- 
sic GDP constituents as separate time-varying indicators.

Keynes [1] introduced household expenditure and domestic savings as elements of GDP in 1936 in his General Theory of Employment, Interest and Money. In 1940 he added government expenditure to GDP in How to Pay for the War [2]. Near the end of World War II in 1944 Keynes proposed "a new world currency, a system of fixed exchange rates between this world currency and the national currencies, and a world central bank that would run the whole system" [3] (p. 14). This proposal was dismissed at the Bretton Woods Conference by American planners who insisted on a dollar-backed fixed exchange-rate system which has since controlled the global economy (http://en.wikipedia.org/wiki/Bretton_Woods_system).

"Shortly before his death on 21 April 1946, Keynes persuaded the powers at the University of Cambridge to create a new Department of Applied Economics. [...] the Cambridge department along with Harvard University's Development Advisory Service would together [...] incubate the first set of ideas around what GDP would look like, and then help to export them to the four corners of the world" [4] (p. 32). American planners then used the Keynesian GDP formula to measure the effect of American aid and to manage European economies. In 1999, mindful of Simon Kuznets' original accounting of distinct goods like cars and cereal boxes by their dollar values [4] (Introduction), the United States Commerce Department proclaimed the GDP formula as the US government's greatest invention of the 20th century.

The severest criticism of GDP has been that it does not measure well-being. "[...] after the end of World War II, [...] Amartya Sen and Mahbub ul Haq would openly revolt against the idea of organizing economies according to GDP. And Haq [...] would lead the design of the United Nations' Human Development Index, which has so far come closest to dethroning GDP” [4] (p. 41). In 1989, Haq's UN team settled on life expectancy, education, and per capita income as the components of the HDI. The last component was insisted on by the "formidable Sen", who resolved the measurement of life expectancy and education in years and income in dollars [4] (pp. 93-95). However, "The HDI, for all its successes, had no discernable impact on the dominance of GDP as the world's principal and most sought-after measure of economic well-being” [4] (p. 101).

Despite GDP's dominance of global economic measurement, in 2008 French president Nicholas Sarkozy railed, "For years people whose lives were becoming more and more difficult were being told that living standards were rising. How could they not feel deceived?" [5] (p. viii). “Mis-Measuring Our Lives. Why GDP Doesn't Add Up [...] argues for a 'dashboard' of indicators that together paint a more accurate picture of a society's well-being. [...] the report makes clear to its readers that HDI [...] was 'the simplest representation' of a broader human development approach that sparked a global revolution in how we measure wellbeing" [4] (p. 159).

In Spain, Marchante, Ortega, and Sánchez found that an augmented HDI regionally converged over 1980-2001, whereas regional disparities in per capita in- 
come remained constant [6]. The HDI measures a nation's health and educational results rather than expenditures, along with its standard of living calibrated by gross per capita income. Resting on Marchante et al., the OECD [7], and the Sarkozy report, Ferrara and Nisticò [8] constructed a well-being index containing another augmented HDI, along with indicators measuring equal opportunity in the labor market, competitiveness, and quality of the socio-institutional context. They found that regional convergence in Italy over 2004-2010 ordered as: their augmented HDI alone, their entire well-being index, and percapita GDP.

Due to the dominance of GDP across the world's economies, this paper analyses its internal consistency and external relation to HDI, which is the most established indicator in Stiglitz, Sen, and Fitoussi's "dashboard” of well-being indicators [5]. Sections 2 and 3 describe GDP and The United Nation's Human Development Index. Section 4 posits the perfect internal consistency and perfect external prediction of any unidimensional index such as GDP. Under this postulation, equally-weighted GDP and differentially-weighted GDP are perfectly correlated and perfectly predict any external criterion variable such as HDI. Section 5 empirically demonstrates the internal consistency of GDP indicators and confirms their precise prediction of HDI in the USA and China. Section 6 discusses the added value that GDP theory, as a special case of unidimensional index theory, brings to the treatment of data from sequential populations. Section 7 emphasizes the value of these newly discovered properties of GDP to developed and developing economies in the $21^{\text {st }}$ century.

\section{Indicators of GDP}

Simon Kuznetz originally formulated national accounts in terms of summative ratio-scaled money. He added up various American income sources and reported his result to the United States Senate in January, 1934 [4] (Prologue, Chapters 2 and 3). "In 1940, six years after Simon Kuznetz had presented his national income estimates to the Senate, Keynes had written down in a table the basis for what today is the formula for GDP" [4] (p. 26). This formula adds up GDP's three macro indicators, which are described by the World Bank as follows (http://beta.data.worldbank.org):

Household final consumption expenditure (current US\$): "Household final consumption expenditure (formerly private consumption) is the market value of all goods and services, including durable products (such as cars, washing machines, and home computers), purchased by households. It excludes purchases of dwellings but includes imputed rent for owner-occupied dwellings. It also includes payments and fees to governments to obtain permits and licenses. Here, household consumption expenditure includes the expenditures of nonprofit institutions serving households, even when reported separately by the country. Data are in current US dollars."

Gross domestic savings (current US\$): “Gross domestic savings are calcu- 
lated as GDP less final consumption expenditure (total consumption). Data are in current US dollars."

The World Bank's update of Keynes' final indicator, added prior to World War II [2] [4] (Chapters 2 and 3), is:

General government final consumption expenditure (current US\$): “General government final consumption expenditure (formerly general government consumption) includes all current government expenditures for purchases of goods and services (including compensation of employees). It also includes most expenditures on national defense and security, but excludes government military expenditures that are part of government capital formation. Data are in current US dollars."

The dollar denomination of variables counted in different units (automobiles, cereal boxes, etc.) allows the ratio scaling of GDP up to a multiplier calibrating GDP in single, thousands, millions, billions, or trillions of current US dollars. This ratio scaling also allows daily exchange-rates to multiply one nation's currency into another's (e.g. dollars into yen, etc.).

\section{The Human Development Index}

The HDI comprises macro indicators that are described by the United Nations Development Program (http://hdr.undp.org/en/data): "The HDI is a summary measure of average achievement in key dimensions of human development: a long and healthy life, being knowledgeable and having a decent standard of living. The HDI is the geometric mean of normalized indices for each of the three dimensions.

The health dimension is assessed by life expectancy at birth; the education dimension is measured by mean of years of schooling for adults aged 25 years and more and expected years of schooling for children of school entering age. The standard of living dimension is measured by gross national income per capita."

In non-UN data life expectancy has been found to correlate positively with education, occupational class, and income from 1971-75 to 2011-14. Gross National Income is also the preponderant correlate of life satisfaction in the 20092012 Gallup World Poll data [10]. The United Nations, like Gallup, uses the logarithm of income to reflect the diminishing importance of income with increasing GNI. The UN then computes its HDI composite as the geometric mean of these three dimensions of well-being.

The United Nations Development Program (http://hdr.undp.org/en/data) continues:

"The normalized $[0,1]$ scale for health and education (in years) and standard of living (in logarithm-of-dollar-units) is obtained as follows:

Minimum and maximum values (goalposts) are set in order to transform the indicators expressed in different units into indices on a scale of 0 to 1 . These goalposts act as the "natural zeros" and "aspirational targets," respectively, from 
which component indicators are standardized ... Having defined the minimum and maximum values, the dimension indices are calculated as the ratio of actual value minus minimum value to maximum value minus minimum value.

For the education dimension, this ratio is first applied to each of the two indicators, and then the arithmetic mean of the two resulting indices is taken...

Because each dimension index is a proxy for capabilities in the corresponding dimension, the transformation function from income to capabilities is likely to be concave-that is, each additional dollar of income has a smaller effect on expanding capabilities. Thus, for income, the natural logarithm of the actual, minimum and maximum values is used".

The conversion of HDI's three dimensions to a common $[0,1]$ scale was accomplished by Amartya Sen [4] (pp. 93-95) [5] (p. xxix). Sen's natural zeros and aspirational targets are calibrated in years for life span and lifetime schooling. For standard of living these goalposts are measured in logarithm-of-dollar-units. The above ratio then places health, education, and standard of living in $[0,1]$. The geometric mean of these three points is the HDI, which is also in $[0,1]$.

Sen's conceptualization of the HDI is based upon national policy results rather than goals. The linkage among HDI's dimensions has recently been supported by van Raalte et al. [11], who report that life expectancy (average at death) ranks perfectly with Finnish educational level and occupational class for nine successive time points over 1970-2015. These authors also found that Finnish life expectancy ranks perfectly with the Finnish income quintile for four successive time points over 2000-2015.

\section{Unidimensional Index Theory}

Our first theoretical goal is to provide an internal quality assurance of GDP. This is especially important in light of the trade war between the United States and China and the resulting slowdown in global GDP growth. Our second goal is to externally relate GDP to welfare by posing HDI as a fractional polynomial regression function of GDP. The closeness of this function of GDP to HDI allows us to assert that GDP is well-being.

\subsection{Internal Consistency of National and Regional Indexes}

The present article uses the GDP indicators in Section 2 as exemplars of unidimensional index theory, which is generalizable to all aggregate American, European, and Chinese indexes. Recent turbulence in these three economies is tracked daily on worldwide television and internet. Other than GDP, the Dow-Jones, S\&P, Nasdaq, Russell, Dollar, and 10 Year Exchange Rate Averages are American financial Indexes tracked by equity traders and the Federal Reserve (cf. MSNBC). The British FTSE, the French CAC, and the German DAX are closely watched European indexes that are candidates for evaluation vis-a'-vis unidimensional index theory (cf. France 24). In Asia the Shanghai Composite Stock Market Index, Hong Kong's Hang Seng, Japan's Nikkei, and the Korea Compo- 
site Stock Price Index are the most influential indexes crying out for quality assurance to global markets (cf. Al Jazeera).

In this plethora of global indexes, GDP looms as the composite most fundamental to the economy of any nation. GDP is so basic, longstanding, and prestigious that market traders, analysts, and policy planners do not recognize the need to quality assure the time series of contemporary Keynesian indicators. Thus, empirical work on GDP has failed to question or examine GDP's own internal structure.

The present article remediates worldwide unawareness that GDP is yet another index also crying out to global markets for quality assurance. Our remediation supplies this assurance by writing a GDP theory as a special case of unidimensional index theory. This theory frequency weights a single indicator over Y successive population sizes for a particular nation. It then finds multiplicative weights which linearly combine the three indicators into a weighted GDP composite. This composite differs from Keynesian GDP, which equally weights the three indicators by summing their dollar-denominated values. It also differs from other indexes, which weight their indicators to maximize the prediction of given criterion variables.

Definition 1. $G_{t j}$ is a nation's GDP indicator $j=1,2,3$ in year $t=1, \ldots, Y . G_{j}$ is the frequency-weighted vector replicating $G_{t j}(j=1,2,3)$ over population $t=$ $1, \ldots, Y$. $G_{j}$ contains $\sum_{t} N_{t}$ values, where $N_{t}$ is the nation's population size in year t. $G_{j}$ is ratio scaled, i.e. unique up to multiplication by a positive scalar.

The second weighting of $G_{j}$ derives from a 2-level principal components analysis, with populations nested within successive years for a given nation:

Lemma 1. $M=a_{1} G_{1}+a_{2} G_{2}+a_{3} G_{3}$ is the first principal component of $G_{1}, G_{2}$, and $G_{3}$ where $\left(a_{1} a_{2} a_{3}\right)$ is the first eigenvector of the covariance matrix of $G_{1}, G_{2}$, and $G_{3}$ [12] [13] (pp. 536-544). The vector $M$ replicates a scalar $m_{t}$ over populations $t=1, \ldots, Y . M$ is a ratio scale unique up to multiplication by a positive scalar.

Definition 2. $a_{1}, a_{2}$, and $a_{3}$ are Eigen weights of vectors $G_{1}, G_{2}$, and $G_{3}$.

Internal-consistency axiom 1 . The correlation matrix of $G_{1}, G_{2}$, and $G_{3}$ is the 3 x 3 unit matrix.

Lemma 2. Under axiom 1 all linear combinations of $G_{1}, G_{2}$, and $G_{3}$ are perfectly correlated over time.

Clearly, axiom 1 and lemma 2 are unrealizable in practice. But they set an ideal against which empirical departures may be evaluated.

Definition 3. $k_{t}=G_{t 1}+G_{t 2}+G_{t 3}$ is a nation's Keynesian GDP in year $t=1, \ldots$, $Y$.

Definition 4. $K$ is the $N_{t}$-weighted vector replicating $k_{t}$ over population $t=$ $1, \ldots, Y . K$ contains $\sum_{t} N_{t}$ values, where $N_{t}$ is the nation's population size in year $t$. $K$ is a ratio scale unique up to multiplication by a positive scalar.

Lemma 2 implies that equally-weighted $K$ and Eigen-weighted $M$ are perfectly correlated over time. 


\subsection{External Prediction of National and Regional Criteria}

Due to the US-China trade war and global GDP deceleration, Fed chairman Powell testified that the well-being of people worldwide is threatened by shrinking US GDP (CNBC 2019, Summer). This link between GDP and aggregate wellbeing motivates our next definitions of frequency-weighted HDI. We then posit this HDI to equal a transformation of Eigen-weighted or equally-weighted gross domestic product:

Definition 5. $h_{t}$ in the interval $[0,1]$ is a nation's HDI in year $t=1, \ldots, Y$. The proportion $h_{t}$ is an absolute scale unique up to identity transformation.

Definition 6. $H$ is the $N_{t}$-weighted vector replicating $h_{t}$ over populations $t=$ $1, \ldots, Y$.

External-prediction axiom 2. $H=f(X)$ for $X=M, K$, where $f$ is a fractional polynomial function [14]. The independent variable $X$ is a ratio scale unique up to mutiplicative transformation calibrating it in single, millions, billions, or trillions of current US dollars. The dependent variable $H$ is an identity scale unique up to multiplication by one.

The conclusions brought by our GDP theory here are burdened by minimal assumptions. This is in part due to axiom 2, which admits a high-order infinity of fractional polynomial functions of $H$ on $X$. For example, a negative acceleration of $H$ on $X$, with sharp downward curvature in $H$, accords with the well-known diminishing marginal utility of money [15] (pp. 411-414). In contrast, a linear polynomial function of $H$ on $X$ has no downward or upward curvature in $H$. The shape of $f$ is of course country specific. In a given country an empirical evaluation of axiom 2 is given by the nearness of its $R^{2}$ to one in a fractional polynomial regression of $H$ on $X$.

Hypothesis. Under lemma 2 and axiom 2, fractional polynomial regressions of $H$ on $X(=M, K)$ give nearly perfect predictions of $H$ by both $M$ and $K$.

Note that $K$ is currently more useful than $M$ in predicting a nation's HDI because $K$ is available in every major nation's records.

\section{Results in the World's Two Largest Economies}

Linearity of $M$ and $K$. The perfect internal consistency of $N_{t}$-weighted indicators $G_{t 1}, G_{t 2}$, and $G_{t 3}$ guarantees a perfect correlation between a nation's manifest principal component $M$ in definition 2 and its Keynesian GDP $K$ in definition 4 . Thus, the actual internal consistency of $N_{t}$-weighted indicators $G_{t 1}, G_{t 2}$, and $G_{t 3}$ governs the actual correlation between $M$ and $K$. Table 1 shows that near-perfect indicator correlations in China produce a correlation of 1.0000 between $M$ and $K$. The slightly lower American correlation 0.9998 is due to the somewhat lower indicator correlations in the USA.

Country Specificity of $M$. The first principal component $M$ in definition 2 has maximum variance among all linear combinations of population-weighted GDP indicators whose squared coefficients sum to one. This conditional maximum variance equals the first eigenvalue of the population-weighted covariance matrix of the three indicators in Section 2. 
Table 1. Correlations of $N_{t}$-weighted indicators $M$ and $K$.

\begin{tabular}{ccccc}
\hline \multirow{2}{*}{ Indicator } & \multicolumn{2}{c}{ USA } & \multicolumn{2}{c}{ China } \\
\cline { 2 - 5 } & $G_{t 2}$ & $G_{t 3}$ & $G_{t 2}$ & $G_{t 3}$ \\
\hline \multirow{2}{*}{$G_{t 1}$} & 0.9505 & 0.9877 & 0.9968 & 0.9996 \\
$G_{t 2}$ & & 0.8934 & & 0.9977 \\
& \multirow{2}{*}{$r(M, K)=0.9998$} & $r(M, K)=1.0000$
\end{tabular}

Lemma 3. The sum of the three eigenvalues of the indicators' covariance matrix equals the sum of the three indicator variances. Thus, the ratio of the first eigenvalue to the sum of the three eigenvalues is the proportion of the total variance of the three indicators accounted for by the first principal component $M$ [13] (pp. 536-538).

Note that in the present application of principal components analysis we are only concerned with the first component. Accordingly, our focus is on the first eigenvalue and the first eigenvector of the covariance matrix of the three GDP indicators described in Section 2. The eigenvalues and eigenvectors of the American and Chinese covariance matrices are exhibited in Table 2 and Table 3. They are produced from the first Stata command [16] in Appendix A1. The second Stata command gives our first principal component $M$.

The second line in Table 2 shows that principal component $M$ accounts for 99.5436406\% of the variance in the three American GDP indicators. This demonstrates that these three classic indicators possess almost perfect internal consistency in measuring Keynesian GDP in the American economy. The eigenvector in the second line of Table 3 contains the optimal national weights for GDP's three indicators in the USA (cf. Section 2). These Eigen weights demonstrate that household consumption most heavily drives $M$ in the American economy.

The third line in Table 2 demonstrates that $99.8561065 \%$ of the variance in China's GDP indicators is attributable to $M$, giving nearly perfect internal consistency. However, the eigenvector in the third line of Table 3 shows a very different profile for these indicators in China than in the USA. American national weights reveal that $M$ is primarily driven by household consumption, with gross domestic savings and government consumption having far lower weights in $M$. In contrast, Chinese national weights show that $M$ is primarily driven by gross domestic savings, with household and government consumption exhibiting much lower weight in $M$ (cf. Section 4.1). The values of the first eigenvectors in Table 3 demonstrate the country-specificity of weighted GDP in the USA and China.

Fractional Polynomial Regressions of $H$ on $K$. The correlations between $M$ and $K$ in Table 1, and the results in Section 5, support our hypothesis that fractional polynomial regressions of $H$ on $X(=M, K)$ give nearly perfect predictions of $H$ by both $M$ and $K$. Due to $K$ s global accessibility, Equation (1) and Equation (2) use $K$ in our fractional polynomial functions. $f(K)$ and $g(K)$ approximate $H$ without measuring it directly:

$$
\text { USA: } H \approx f(K)=0.0317122 K^{0.5}+0.7856233
$$


Table 2. Eigenvalues for $M$.

\begin{tabular}{cccc}
\hline Principal Components & 1 & 2 & 3 \\
\hline American Eigenvalues & 7.53267 & 0.0337443 & 0.000789345 \\
Chinese Eigenvalues & 4783248 & 6794.73 & 98.4603 \\
\hline
\end{tabular}

Note. The sum of the three eigenvalues is the total variance in the three GDP indicators. This is 7.5672036 in the USA and 4,790,141.19 in China. The percent of indicator variance accounted for by the first principal component is $99.5436406 \%$ in the USA and $99.8560963 \%$ in China. Each percent is $100 \times$ the ratio of the first eigenvalue to the sum of that nation's three eigenvalues [13] (pp. 536-538).

Table 3. First eigenvectors for $M$.

\begin{tabular}{cccc}
\hline Nation & Household Consumption & Gross Domestic Savings & Government Consumption \\
\hline USA & 0.9603 & 0.1803 & 0.2131 \\
China & 0.5712 & 0.7939 & 0.2087 \\
\hline
\end{tabular}

Note. The squared scoring coefficients in each row sum to one. The tabled values weight each nation's three indicators in computing that nation's first principal component $M[13]$ (pp. 536-538).

China: $H \approx g(K)=0.2622926 K^{0.5}-0.057356 K^{0.5} \ln K+0.3135376$

The bivariate regression of $H$ on $K^{0.5}$ (not shown) for the USA has intercept 0 and slope 1. The trivariate Chinese regression of $H$ on $K^{\oplus .5}$ and $K^{0.5} \ln K$ (not shown) has an intercept and slope closely approaching 0 and 1 . Thus, $f(K)$ and $g(K)$ are virtually identical to $H$ in the USA and China.

$g(K)$ in Equation (2) is a fractional polynomial function quite distinct from $f(K)$ in Equation (1). Both functions give close empirical support to our hypothesis in Section 4.2. They also validate the country specificity of $f(K)$ and $g(K)$ in the world's two largest economies. The fitted $R^{2}$ s for $f(K)$ and $g(K)$ are 0.9862 and 0.9924 in the USA and China. The larger $R^{2}$ for China comports with its higher indicator correlations in Table 1. Interestingly, comparably high Chinese $R^{2}$ s attend several other fractional polynomial functions of $K$, which also closely approximate $H$. These ancillary functions, although more unsightly than $g(K)$ in (2), are equally useful in approximating well-being in the absence of UN human development data. Thus, the approximation of $H$ by a function of $K$ is not unique in the class of fractional polynomial transformations of $K$. We also note that these other approximating functions are invariant up to multiplication of $K$ by a positive constant, i.e. these functions are independent of the scaling of K.

Figure 1 and Figure 2 plot $H$ on $K$. Figure 1 shows only slight downward concavity, indicating American household and government spending that is well beyond people's needs. This result reiterates American insistence upon "the almighty dollar" as the global standard at Bretton Woods in 1944 [3] [4]. In contrast, Figure 2 demonstrates a sharply diminishing marginal utility for money in Chinese society, with little change in $H$ beyond its sizable increases driven by initial increments in $K$. The fitted plots of $H$ on $K$ in Figure 1 and Figure 2 are virtually identical to those for $H$ on $M$ (not shown). 


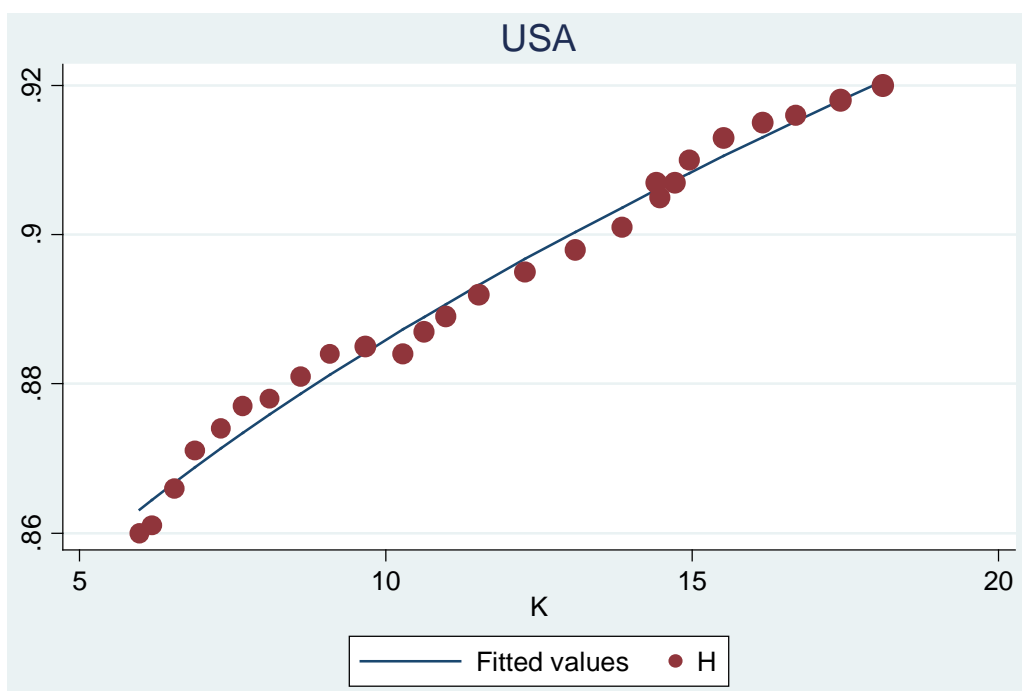

Figure 1. $H$ is in $[0,1]$ and $K$ is in trillions of current US dollars.

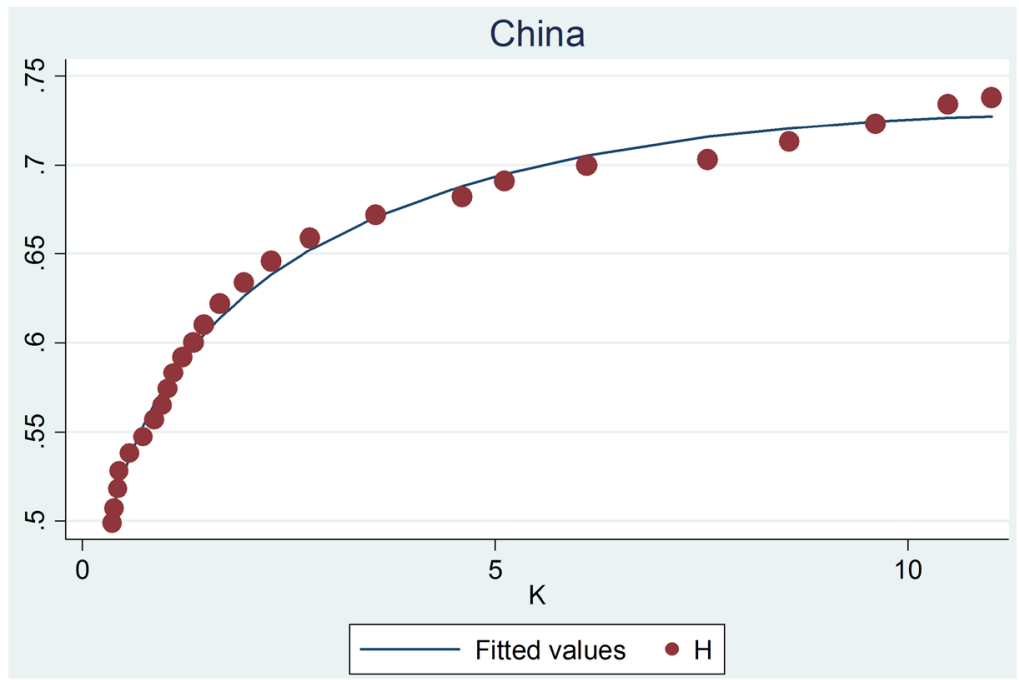

Figure $2 . H$ is in $[0,1]$ and $K$ is in trillions of current US dollars.

As already noted, the extremely close fit of both functions in Figure 1 and Figure 2 strongly supports our hypothesis in Section 4.2, and validates the country specificity of $f(K)$ and $g(K)$. These results demonstrate that Keynesian $K$ is a near perfect proxy for well-being $H$. Thus, $K$ can replace the UN's HDI in the USA and China. It remains to be shown if GDP proxies HDI in the other 18 nations of the G20.

\section{Discussion: Advantages of Objective over Subjective Indicators}

\subsection{Data Definition}

Unidimensional index theory overrides "The central dogma of statistical inference, that there is a component of randomness in data. Neither denying nor quantifying uncertainty, we simply ignore it." [12] (p. 8 of 11). This axiomatic 
approach to sequential populations brings compelling advantages to social and financial data science. Probabilistic inference is replaced by parameter computation and random variables give way to real variables. This suggests further "statistical thinking and new foundational frameworks" that help sort out "the many philosophical issues data science presents ..." [17]. This call has been echoed by the American National Science Foundation, who has "released a revised version of the solicitation 'Critical Techniques and Technologies for Advancing Foundations and Applications of Big Data Science ..." [18].

Pfeffermann observes that "The use of big data does not require a sampling frame, questionnaires, interviews, and all the other ingredients underlying survey samples ... this should be the ultimate target of every country-having sufficiently accurate administrative records so that no population censuses will be needed" [19] (pp. 433, 455).

Horrigan also views Big Data as non-sampled data "from electronic sources whose primary purpose is something other than statistical inference ... this type of Big Data typically comprises the universe and, by definition, can represent (nearly) the entire population ..." [20] (pp. 25-26). As examples of non-sampled universe files Horrigan mentions daily price indexes, point-of-sale retail databases, universe data on hospitals, and corporate data. Similarly, unidimensional index theory exploits the electronic files of the World Bank and the United Nations Development Program to verify axioms 1 and 2 with vectors $M, K$, and $H$.

\subsection{Data Collection}

For almost half a century the interrogation of individuals with survey samples has been shadowed by skepticism about the incremental benefits of subjective indicators over and above objective indicators already in use [21] [22]. The problems associated with subjective measurement [23] point up the pitfalls of survey sampling, which may not be needed in the first place.

Our hypothesis in Section 4.2, tested in Section 5, evades the host of long-standing, and now acute, issues daunting micro-data sampling. First, sampled micro data are beset by the unresolved competition between randomization-based and model-based regression [24] [25]. Second, both types of regression face problems of measurement error [26], sampling error [27] [28] [29], unit nonresponse [30], missing data [31], and variance estimation [32] [33]. Unit nonresponse alone threatens the entire survey industry due to public unwillingness to answer mail, telephone, internet, or face-to-face questions. The host of problems associated with survey measurement and process quality were discussed and illustrated over two decades ago in the volume edited by Lyberg et al. [23]. Today Bradburn laments that "... the challenges confronting the survey researcher are dominated by the difficulty in locating sample persons and getting them to respond at all.” [34] (p. 94).

\subsection{Data Analysis}

Unidimensional index theory in Section 4 is written to be vulnerable to empiri- 
cal verification with respect to $M, K$, and $H$. This verification rests on the data analysis of these $N_{t}$-weighted vectors, which represent the USA's and China's sequential populations from years $1, \ldots, Y . N_{t}$ is the American and Chinese population size in year $t$. Note vectors $M, K$, and $H$ each contain $\sum_{t} N_{t}=7.481$ billion elements in the USA and $\sum_{t} N_{t}=33.082$ billion elements in China.

Internal consistency axiom 1 in Section 4.1 posits three $N_{t}$-weighted indicators that are perfectly correlated. The first principal component $M$ of these indicators is quality assured and Eigen-weighted in allocating a nation's GDP.

External-prediction axiom 2 in Section 4.2 relates the Keynesian explanatory vector $K$ to the United Nation's criterion vector $H$. Empirical support of axiom 2 is provided by the near identity of vectors $H$ and $K$ and $R^{2} \approx 1$ in a fractional polynomial regression of $H$ on $K$. This data analysis allows the transformed $K$ in Equation (1) and Equation (2) to replace the HDI proxy for well-being, circumventing the measurement of HDI itself. This result in other major nations would help resolve the debate about GDP and well-being, as well as simplify global data processing.

\section{Conclusions}

Equally weighted and Eigen weighted GDP are perfectly correlated in China and nearly perfectly in the USA. Eigen-weighted GDP signals a nation's economic profile, while equally-weighted GDP remains in place for conventional analysis of economic data. Equally-weighted GDP will be preferred due to its availability in most national accounts.

These new properties of equally-weighted and Eigen-weighted GDP are also useful in a more general theory of national constructs. In this article GDP and HDI are aggregated from national indicators correlated over time. In other applications constructs may be correlated over, say, the G20 nations at a single time point to take a snapshot of cross-national differences among developed and developing countries [22]. Moreover, constructs may be geographical, bio-medical or socio-political as well as the GDP and HDI indexes treated here.

Finally, Keynes' equally-weighted GDP remains a nation's dominant policy informant. For some years now the USA Federal Reserve's Board of Governors has been negotiating with the Congress in order to add a third mandate to their longstanding missions of reducing unemployment and inflation. Fed Chairman J. Powell described this new mandate as the mitigation of falling GDP

(www.reuters.com/video/2019/07/10/powells-testimony-raises-hopes-of-rate-c?v ideoId $=572792782$ ). In view of the broad agreement that the transpacific trade war reduces GDP worldwide

(https://www.federalreserve.gov/newsevents/testimony/powell20190710a.htm), as well as our finding that GDP is well-being, it follows that economic turbulence lowers human development everywhere. The world and its data call on the United States and China to stop their trade war. The consequent well-being of nations will affect the $21^{\text {st }}$ century more than Keynesian GDP influenced the $20^{\text {th }}$ century in which it was born. 


\section{Acknowledgements}

This article is dedicated to my best critic, Maria Cohn Bechtel. The author thanks Dr. Bethany Bechtel for her gift [4] that alerted him to the importance of GDP to us all, and for her insistence on monitoring a nation's economic indicators over time.

This adaptation of [12] [35] improves upon [35] by parsimoniously linking GDP to the United Nation's Human Development Index.

\section{Conflicts of Interest}

The author declares no conflicts of interest regarding the publication of this paper.

\section{References}

[1] Keynes, J.M. (1936) The General Theory of Employment, Interest and Money. Harcourt, Brace \& World, New York.

[2] Keynes, J.M. (1940) How to Pay for the War. Macmillan, London, UK.

[3] Varoufakis, Y. (2016) The Weak Suffer What They Must? Europe's Crisis and America's Economic Future. Nation Books, New York.

[4] Masood, E. (2016) The Great Invention: The Story of GDP and the Making and Unmaking of the Modern World. Pegasus Books Ltd., New York.

[5] Stiglitz, J., Sen, A. and Fitoussi, J.-P. (2010) Mismeasuring Our Lives: Why GDP Doesn't Add Up: The Report of the Commission on the Measurement of Economic Performance and Social Progress. New Press, New York.

[6] Marchante, A.J., Ortega, B. and Sánchez, J. (2006) The Evolution of Well-Being in Spain (1980-2001): A Regional Analysis. Social Indicators Research, 76, 283-316. https://doi.org/10.1007/s11205-005-1097-6

[7] OECD (2017) How's Life? 2017: Measuring Well-Being. OECD Publishing, Paris.

[8] Ferrara, A.R. and Nisticò, R. (2013) Well-Being Indicators and Convergence across Italian Regions. Applied Research in Quality of Life, 8, 15-44. https://doi.org/10.1007/s11482-012-9180-z

[9] Ferrara, A.R. and Nisticò, R. (2015) Regional Well-Being Indicators and Dispersion from a Multidimensional Perspective: Evidence from Italy. The Annals of Regional Science, 55, 373-420. https://doi.org/10.1007/s00168-015-0704-y

[10] Graham, C. and Nikolova, M. (2015) Bentham or Aristotle in the Development Process? An Empirical Investigation of Capabilities and Subjective Well-Being. World Development, 68, 163-179. https://doi.org/10.1016/j.worlddev.2014.11.018

[11] van Raalte, A.A., Sasson, I. and Martikainen, P. (2018) The Case for Monitoring LifeSpan Inequality. Science, 362, 1002-1004. https://doi.org/10.1126/science.aau5811

[12] Bechtel, G.G. (2017) New Unidimensional Indexes for China. Mathematical and Computational Applications, 22, 13. https://doi.org/10.3390/mca22010013

[13] Johnston, J. (1984) Econometric Methods. 3rd Edition, McGraw-Hill, New York.

[14] Royston, P. and Altman, D.J. (1994) Regression Using Fractional Polynomials of Continuous Covariates: Parsimonious Parametric Modeling (with Discussion). Applied Statistics, 43, 429-467. https://doi.org/10.2307/2986270

[15] Samuelson, P. and Nordhaus, W. (1985) Economics. 12th Edition, McGraw-Hill, New York.

[16] StataCorp (2011) Stata Statistical Software, Release 12. StataCorp LP, College Station, TX. 
[17] Davidian, M. (2013) Aren't We Data Science? Amstat News, July, 3-5.

[18] Vogelius, M., Kannan, N. and Huo, X. (2015) NSF Big Data Funding Opportunity for the Statistics Community. Amstat News, April, 6.

[19] Pfeffermann, D. (2015) Methodological Issues and Challenges in the Production of Official Statistics: 24th Annual Morris Hansen Lecture. Journal of Survey Statistics and Methodology, 3, 425-467. https://doi.org/10.1093/jssam/smv035

[20] Horrigan, M.W. (2013) Big Data: A Perspective from the BLS. Amstat News, January, 25-27.

[21] Shapiro, H. (1972) The Index of Consumer Sentiment and Economic Forecasting: A Reappraisal. In: Strumpel, B., Morgan, J.N. and Zahn, E., Eds., Human Behavior in Economic Affairs, Jossey-Bass, San Francisco, CA.

[22] Bechtel, G.G. (2016) National Index Theory: Chomskyan Globalization and Well-Being. Computational and Applied Mathematics Journal, 2, 6-11.

[23] Lyberg, L., Biemer, P., Collins, M., de Leeuw, E., Dippo, C., Schwarz, N. and Trewin, D. (1997) Survey Measurement and Process Quality. Wiley and Sons, New York. https://doi.org/10.1002/9781118490013

[24] Chaudhuri, A. and Stenger, H. (2005) Survey Sampling: Theory and Methods. 2nd Edition, CRC Press, Boca Raton, FL. https://doi.org/10.1201/9781420028638

[25] Opsomer, J.D. (2009) Introduction to Part 4: Alternative Approaches to Inference from Survey Data. In: Pfeffermann, D. and Rao, C.R., Eds., Handbook of Statistics. Sample Surveys. Inference and Analysis, Elsevier, Amsterdam.

[26] Bound, J., Brown, C. and Mathiowetz, N. (2001) Measurement Error in Survey Data. In: Heckman, J.J. and Leamer, E., Eds., Handbook of Econometrics, Elsevier Science, Amsterdam, 3705-3843. https://doi.org/10.1016/S1573-4412(01)05012-7

[27] Thompson, M.E. (1997) Theory of Sample Surveys. Chapman and Hall, London.

[28] Lohr, S.L. (2010) Sampling: Design and Analysis. 2nd Edition, Brooks/Cole, Boston.

[29] Brick, J. and Montaquila, J.M. (2009) Nonresponse and Weighting. In: Pfeffermann, D. and Rao, C.R., Eds., Handbook of Statistics (Sample Surveys. Design, Methods and Applications), Elsevier, Amsterdam, 163-185. https://doi.org/10.1016/S0169-7161(08)00008-4

[30] Frankovic, K.A., Panagopoulos, C. and Shapiro, R.Y. (2009) Opinion and Election Polls. In: Pfeffermann, D. and Rao, C.R., Eds., Handbook of Statistics (Sample Surveys: Design, Methods and Applications), Elsevier, Amsterdam, 567-595. https://doi.org/10.1016/S0169-7161(08)00022-9

[31] Little, R.J.A. and Rubin, D.B. (2002) Statistical Analysis with Missing Data. Wiley and Sons, New York. https://doi.org/10.1002/9781119013563

[32] Demnati, A. and Rao, J.N.K. (2004) Linearization Variance Estimators for Survey Data. Survey Methodology, 30, 17-26.

[33] Prášková, Z. and Sen, P.K. (2009) Asymptotics in Finite Population Sampling. In: Pfeffermann, D. and Rao, C.R., Eds., Handbook of Statistics (Sample Surveys. Inference and Analysis), Elsevier, Amsterdam, 489-522. https://doi.org/10.1016/S0169-7161(09)00240-5

[34] Bradburn, N. (2016) Surveys as Social Interactions. Journal of Survey Statistics and Methodology, 4, 94-109. https://doi.org/10.1093/jssam/smv037

[35] Bechtel, G.G. (2018) The Human Development Index as Isoelastic GDP: Evidence from China and Pakistan. Economies, 6, 32.

https://doi.org/10.3390/economies6020032 


\section{Appendix A1. First Principal Component $M$ of the Keynesian Indicators}

Axiomatic computation (rather than estimation) of population parameters is carried out on the three time-series of indicators for the USA and China supplied by the World Bank (http://beta.data.worldbank.org). The findings in Table 2 and Table 3 are brought by 2-level principal components theory in Section 4.1 and its empirical application in Section 5:

The first of the following two Stata commands [16] lists the three dollar-denominated GDP indicators in Section 2:

pca hhspend savings govspend [fweight $=$ popt], covariance predict $M$

The first Stata command operates on $26 \times 4$ American and Chinese spreadsheets with rows labeled 1990 ... 2015 and columns labeled population, household expenditure, gross domestic savings, and government expenditure. popt is population size, calibrated in millions, over 26 successive American and Chinese populations in years 1990 ... 2015. The optional qualifier [fweight = popt] poptweights variables hhspend, savings, and govspend, expanding them to run over $i$ $=1, \ldots$, pop $_{t}$ for $t=1990, \ldots, 2015$. The option covariance calls for a 2-level principal components analysis of the covariance matrix of these three expanded variables in the USA and China. These expanded variables are measured in trillions of current US dollars.

The second Stata command gives the first 2-level principal component $M$ of hhspend, savings, and govspend in the USA and China.

\section{Appendix A2. Fractional Polynomial Regressions of $H$ on $K$}

The UN time series $H$, described in Sections 3 and 4.2, is obtained from the United Nations Development Program (http://hdr.undp.org/en/data). The time-series $K$ of Keynesian GDP is supplied by the World Bank (http://beta.data.worldbank.org). Fractional polymonial functions of $H$ on $K$ are returned by the following bivariate and trivatiate regression commands:

USA: fracpoly, degree(1) noscaling adjust(no): regress $H K$ [fweight = popt]

China: fracpoly, degree(2) noscaling adjust(no) powers $(.5, .5)$ :

regress $H K$ [fweight $=$ popt]

These Stata commands [16] operate on a $26 \times 3$ spreadsheet with rows labeled $1990 \ldots 2015$ and columns labeled population, $H$, and $K$. popt is population size, calibrated in millions, over 26 successive American and Chinese populations in years 1990 ... 2015. The fracpoly optional qualifiers retain the calibration of $K$ in trillions of current US dollars. The three fracpoly qualifiers for the USA command return the fractional polynomial function in Equation (1). The four fracpoly qualifiers for the China command return the fractional polynomial function in Equation (2). The optional qualifier [fweight = popt] for the regress command 
popt weights variables $H$ and $K$, expanding them to run over $i=1 \ldots$ pop $_{t}$ for $t=$ $1990 \ldots$ 2015. The expanded variable $K$ is measured in trillions of current US dollars. The expanded variable $H$ is measured on Sen's $[0,1]$ scale described in Section 3 [4] (pp. 93-95) [5] (p. xxix). 